\title{
Age groups of De'ang people from a comparative perspective: a case study of De'ang people in Yunnan Province, China
}

\section{Yu Shu ${ }^{1}$}

Received: 8 November 2021 / Accepted: 3 January 2022 / Published online: 08 February 2022 (c) The Author(s) 2022

\begin{abstract}
Based on comparison between age sets in Africa and the social age structure of the Dai people in China, this paper examines the forms, functions and evolution of the age groups of the De'ang people in Yunnan Province, China. The age groups of De'ang people are unique in that only two distinct age grades (the youth and the elderly) are organized, both of which have different social functions. This pattern provides an important reference for further discussion on the relationships between age sets and age grades, as well as forms and types of age-class systems.
\end{abstract}

Keywords Age groups $\cdot$ De'ang people $\cdot$ Age class system $\cdot$ Age grades

\section{Introduction}

As a unique ethnic group with a small population of over 20,000 in Yunnan Province, China, the De'ang ethnic group mainly lives in the border area between China and Myanmar. There are several branches of this group, and the residences of De'ang people are scattered throughout the region. As the only De' ang township in China, Santaishan De'ang Township, Mangshi City, Dehong Dai and Jingpo Autonomous Prefecture, Yunnan Province, is one of the most concentrated communities of De'ang people in China. Due to the historical long-term rule of tusi (hereditary tribal leaders) over the Dai people and the profound influence of Dai culture, De' ang people practice Theravada Buddhism and use the Dehong Dai language. Three ethnic groups, namely the De'ang, Jingpo and Han, reside in Santaishan De'ang

Yu Shu

shuyu0820@126.com

1 Institute of Ethnology and Anthropology, Chinese Academy of Social Sciences, No.27, Zhongguancun Nandajie Street, Haidian District, Beijing 100081, China 
Township, and each village community tends to be dominated by a single ethnic group. In Chudonggua Village, there are 292 households, containing a total of 1235 De' ang people. The De' ang language, of which there are several dialects, belongs to the Deangic branch of the Mon Khmer group of the Austro-Asiatic language family. Although the majority of De'ang people in Chudonggua Village speak one of two different dialects, they are able to communicate with each other.

During my field studies, villagers would frequently mention "the youth group" and "the elderly group". For example, "so-and-so is the leader of the youth group (the elderly group)", "the youth group is responsible for performing the water drum", "the elderly group manages the kyaung (Buddhist temple)", "the time of the Water Splashing Festival is worked out by the elderly group", and so on. The terms for "the youth group" and "the elderly group" in De' ang language are "a lian a pia" and "bay ta? $\mathrm{za}^{\text {? }}$ gai", ${ }^{1}$ respectively. The former means "lads and young ladies", and the latter means " elderly men and women". With increased external communication, the Chinese expressions for "the youth group" and "the elderly group" have become familiar to and accepted by villagers. While these appellations are often heard during villagers' exchanges with outsiders, they still use the corresponding names in the De'ang language when communicating with each other. "The youth group" and "the elderly group" are key categories of groups in social life of the De'ang people. The youth group is particularly special in that the young men and women who join it must be paired up to create compulsory "ku" partnerships. The organizational forms of "the youth group" and "the elderly group" of De' ang people in Santaishan De'ang Township are seldom found in ethnic groups inhabiting the adjacent areas. What are the similarities and differences between these age groups and age sets with those that anthropologists have previously studied?

According to the definition in A Dictionary of Cultural Anthropology published by Oxford University Press in 2018, an age-class system is: "the organization of individuals (in most cases men) into formal groupings by age ('age sets') that pass through defined life stages ('age grades') and even live together. These stages, which are tied to both biological changes (puberty) and socially recognized events (such as marriage or the birth of a child), can include initiation, warriorhood, adulthood, and status as elders, each carrying distinct rights and obligations. In a number of East African societies, age grades are central elements of the social structure and political processes. The age class system promotes social solidarity beyond kin groups, and members of age sets typically remain closely associated throughout their whole lives." (Vivanco 2018).

Age-class systems are most prevalent in East Africa, Central Brazil and parts of New Guinea. The results of research involving age sets in Africa are most notable. In 1954, S. N. Eisenst Adt conducted a comparative study of 37 societies using age sets on the African continent in an attempt to provide some general insight into their

\footnotetext{
1 The terminologies specific to De'ang people that appear for the first time in this paper are marked international phonetic symbols. The international phonetic symbols were marked with the assistance of Mr. Chen Guoqing at the Ethnolinguistic Research Department, the Institute of Ethnology and Anthropology, Chinese Academy of Social Science. The author would like to thank him for his help.
} 
organizational forms, conditions of emergence, social functions and structural differences. He pointed out that the formation of age sets was based on chronological age, with each member of the society being able to join after reaching a certain age. The system primarily served to complete the socialization process, realize the intergenerational transmission of social behaviors and values, and enhance peoples' social identities to ensure social stability and continuity. The degree of development and structural differences of age sets were closely linked to the differentiations between and specializations of social roles. In a society with little specializations and no dedicated political or military institutions, basic functions such as politics and military were attributed to members of different age sets. This differed in societies with and without kingship (Eisenst 1954).

In the 1940s, Tien Ju-Kang developed the concept of the "social age structure" in his research on Namu Village in Mangshi City, Dehong Dai and Jingpo Autonomous Prefecture, Yunnan Province. He argued that although social age structures were similar to age sets, there were obvious differences between them (Tien 2008). The social age structure referred to four progressive life stages in the social life of Dai people, i.e., the "four social age grades". These four social age grades did not represent natural maturity and aging, but rather social identities and the rights and obligations of these. The transformation of social age grades was realized through the social mechanism of the "bloi" ritual ${ }^{2}$ (Tien 2008), during which people would give alms to Buddhist temples in order to earn merit. In a subsequent restudy, scholar Chu Jianfang clearly indicated that the "social age structure" introduced by Tien JuKang did not resemble the age sets defined by traditional anthropology, but that age sets formed according to chronological age existed in Namu Village (Chu 2005). In recent years, existing age sets have been discovered during field investigations on the Bai people (Luo 2008; Ma 2015), the Tibetan people (Yejingmuzhu 2010), and the Amis people in Taiwan (Huang 2000). Although age sets are a common form of social organization, their specific forms, rules and social functions vary in different societies. In addition, while the "teenage companions" and "sister companions" discovered in Hui' an County, Fujian Province, may resemble age sets, these are more like gender-based organizations formed for emotional support, related to the marriage custom whereby women are required to live with their parents for a long period after getting married. (Wu 1999).

In reality, the "social age structure" proposed by Tien Ju-Kang is more reminiscent of the age grades found in East Africa. Following the development of research on age class systems, the distinctions between "age set" and "age grade" have been gradually emphasized in studies carried out since the 1970s. This change is also reflected in the above-quoted definition from A Dictionary of Cultural Anthropology published by Oxford University Press in 2018. According to this definition, age grades refer to a series of life stages in which persons assume different social identities at multiple stages of their lives, and can be promoted to higher age grades individually or collectively. Meanwhile, age sets are formal social organizations to

\footnotetext{
${ }^{2}$ The word "blbi" originates from Burmese means "assembly". It is the name used by Tien Ju-Kang to describe a category of religious ritual activities of Dai people.
} 
which persons are permanently attached, and they can only be transferred or promoted to other age sets collectively. (URL for Wikipedia) According to Frank H. Stewart in his attempt to summarize the different characteristics of age sets and age grades, age sets are characterized by sequencing, a lack of overlapping, singular membership, accession, dissolution, inability to resign and inability to rejoin. Meanwhile, age grades are successive sequences without intervals, with each grade involving distinctive activities (Stewart 1977). ${ }^{3}$ Despite their distinctions, age sets and age grades are in fact closely related, as demonstrated by their various combinations in different societies. For example, the Nuer people have no age grades except for a coming-of-age ceremony marking the transition from childhood to adulthood. As one elderly age set fades away, the successive one will automatically replace it, and specific activities are not assigned to age sets by age grades. In other tribal societies, specific activities are allocated for different age sets by age grades. Therefore, military training and preparation for military expeditions for young people is provided in age grades. For example, the Nandi people in Kenya have seven male age sets - two for boys, one for warriors and four for elders. A warrior age set in charge of warfare will be upgraded to an elder age set after retaining its position for approximately 15 years, and tribal authority will be handed over to the incoming warrior age set. (Encyclopedia Britannica Online).

\section{Methods}

Based on comparison between age set systems in Africa and the social age structure of the Dai people, this paper primarily uses field studies to provide in-depth analysis on the age groups of the De'ang people in terms of their forms, functions, and evolution.

In April-May 2017, April and October 2018, and February 2019, the author conducted multiple field studies in the De'ang villages in Dehong Dai and Jingpo Autonomous Prefecture, Yunnan Province. The main focus was on the two administrative villages of Chudonggua and Bangwai in Santaishan De'ang Township, Mangshi City, and the village communities of Feishunha, Feigang, and Mangbang in Zhangfeng Township, Longchuan County. ${ }^{4}$ The author used the International Phonetic Alphabet to notate the key concepts related to the age groups of the De'ang people. In order to compare the field materials on the De'ang people with other related studies, the author has extensively reviewed the existing literature on age set studies. In addition, in order to trace the evolution of the age groups of the De'ang people, the author has referred to early research on the region to expand the historical perspective of the study, and adopted methods of historical anthropology through comprehensive use of historical documents such as local chronicles and socio-historical surveys.

\footnotetext{
3 Stewart, Frank H. 1977. Fundamentals of Age-group Systems, New York: Academic Press. p.28-29, pp.130-131.

4 All materials in this article that are not explicitly attributed are from these field studies.
} 


\section{Results and discussion}

Based on the clear distinction between age grades and age sets, this paper seeks to provide in-depth analysis on the forms and functions of the age groups of the De'ang people in Santaishan from a comparative perspective, and to trace their historical evolution through the lens of historical anthropology. In this paper, "age groups" refers to the organization of age grades.

\section{The four age grades of the De'ang people}

The De'ang people in Santaishan divide the social life of an individual into four stages (age grades). In the first stage, which lasts from birth to adulthood, girls are referred to as "kon a pia" and boys as "kon a liay". At this stage, individuals are in a stage of familial upbringing and personal growth, with no excessive family burdens or social responsibilities. As soon as girls learn to walk, they begin wearing tube skirts. They do not wear traditionally wear queues, but keep their heads shaved from childhood, with the exception of short bangs on their foreheads. Boys wear small pigtails on the tops of their heads, and the rest of their hair is shaved.

The second stage is marked by a rite of passage. At this stage, young women and men, mostly aged 15-16, are referred to as "a pia" and "a lian", respectively. Lacquered teeth for women and tattoos for men are important aspects of this rite of passage. The most distinctive change in costume during this period is that both men and women begin wearing head wraps and earspools (in the left earlobe for men and both earlobes for women). It is during this period that "a liay" and "a pia" join the youth age group. After doing so, they begin to participate in the "bloi", 5 for which they provide labor, perform required rituals, and begin to acquire titles. The title system of the De'ang people consists of three ascending tiers: "mr/mau", " $\mathrm{t}$ ha:m", and "pha ka". The first level, "mr/mau" is the most junior title, which young men and women can earn by participating in public "bloi" (e.g., building kyaungs, sculpting Buddhas, building pagodas, etc.) or assisting their families with "bloi" duties. The titles "mr", and "mau", meaning leaf and flower, respectively, and are given to "a lian" and "a pia". Various suffixes can be added to these to form new titles such as "mr rn", (meaning "golden leaf"), "mr k $\mathrm{h}^{\mathrm{h}} \mathrm{m}$ " (meaning "silver leaf"), and "mr cian" (meaning "treasure leaf").

The third stage is marked by marriage. At this point, young men and women automatically withdraw from the youth age group and enter a marital period focused on household production, labor, childbearing, child rearing, and supporting the elderly. Married women are collectively known as " $\mathrm{qa}^{\text {? }}$ mai ' $\mathrm{i}$ " and married men as " $\mathrm{ta}^{\text {? }} \mathrm{kun}$ 'i”. Women wear simple hairstyles and clothing after marriage. They shave their heads, removing their forehead bangs, and no longer adorn their head wraps and earspools with colored pompoms. Married men and women focus on providing for their families and doing productive work. They still participate in public events such

\footnotetext{
5 The meaning of the "bloi" among the De'ang people is almost the same as that among the Dai.
} 
as the "bloi" in the village, but not as main organizers or service providers. In fact, the most important work they do at this stage consists of accumulating funds for the "bloi". For the De' ang people in Santaishan, apart from the public "bloi" (which is organized in the collective name of the village), there are two types of private "bloi", namely "lu? t6om" and "lu? s $r$ tan". The former is performed for deceased parents in order to express gratitude and pray for their entry to the Pure Land; the latter is performed to gain merit, higher titles and a better afterlife. In the opinion of the locals, the former must be completed before the latter can be performed. Anyone who does not adhere to this standard will be shamed and disgraced in society. In addition, "lu? s $\gamma$ tan" cannot be performed by a person whose parents are still alive, regardless of their age. By performing or participating in the "bloi" during this period, a person can earn the second-tier title " $\mathrm{t}$ a:m", which can also be distinguished by suffixes, such as "tha:m ciay", "tha:m rn" and "tha:m kh"

The fourth stage is marked by entering kyaungs to worship the Buddha, and a gradual move away from worldly life. During this period, the elderly (the women and men of whom are respectively referred to as " $\mathrm{za}^{2}$ " and " $\mathrm{ta}$ ") can no longer physically bear the heavy workload of production, and their children are getting married and settling down to bear and raise children. Older women dress more plainly, with no floral patterns or embroidered pompoms decorating their head wraps, tops, or tube skirts, which only feature patterns marking their clanship. The costume for men changes slightly in different stages of life, mainly in the color of their tops. Young men usually wear white and blue tops, while older men tend to wear black tops, white headbands, and black wide-legged shorts over leg wraps. Older people aspire to accumulate merit, gain higher titles and obtain a better afterlife by persistently performing the "bloi", which leads to " $\mathrm{p}^{\mathrm{h}} \mathrm{a} \mathrm{ka}$ ", a title that is further divided into three tiers: "pha ka tcuan", "pha ka loi", and " $\mathrm{p}^{\mathrm{h}}$ a ka loi tcik cian". The highest title achievable by participating in a public "bloi" is " $\mathrm{p}^{\mathrm{h}} \mathrm{a}$ ka loi", which is granted to a small number of 70-year-olds, who wear white clothing during "bloi" events. Others cannot be referred to as " $\mathrm{p}^{\mathrm{h}_{\mathrm{a}}} \mathrm{ka}$ bi", regardless of their contribution to the public "bloi". The supreme title is " $\mathrm{p}^{\mathrm{h}}$ a ka loi tcik cian", which can only be obtained by performing private "bləi". No one in Chudonggua Village has received this title as of yet. Alternatively, individuals can earn the title of "pha ka" —only up to "ph a ka bi"-by performing "lu? t6om" for their deceased parents.

The four age grades of the De'ang people are precisely what Tien Ju-Kang referred to as the "social age structure". According to Tien's definition, the social age structure is essentially a sequence of social life histories: "In contrast to the definite 'age sets' in which members of society are linked exclusively by chronological age, what determines the social age structure of the Dai people is not age sets, but the sequence of social life histories reflected in the 'bloi'." (Tien 2015). Although Tien Ju-Kang was keenly aware of the distinct difference between social age structure and age sets, he did not elaborate on the distinction between age sets and age grades, nor the varying combinations of the two in different societies, some of which use age grades but not age sets, the opposite, or both.

In his restudy of Namu village, Chu Jianfang pointed out the co-existence of age sets according to chronological age, which the locals called "Daiguo". Each "Daiguo" generally covered an age span of 3 to 5 years, and, through merging and 
regrouping, could gradually spread from one neighborhood to the entire village. The "Daiguo" groups were named, and some of them had subgroups. Daiguo members would collectively participate in public activities such as organizing the "bloi", weddings, funerals, labor exchanges, participating in the "bloi" events of other villages, and so on (Chu 2005). This suggests that different social age grades corresponded to a varying number of age sets, and that the Dai people in Namu village used both age grades and age sets.

\section{Forms and functions of the age groups of De'ang people}

Forms of the youth and elderly age groups De'ang age groups are distinguished by the fact that not every age grade necessarily has its organizational form. The author found that only the second age grade (second social age grade) and the fourth age grade (fourth social age grade) had corresponding age group organizations, known as the youth age group and the elderly age group. The young people in the second age grade remain as members of the youth age group until they get married, and individuals in the third age grade who do not visit temples or worship the Buddha will be denied entry to the elderly age group. The youth and elderly age groups are organizations embedded in a social age structure, with distinctive features in terms of their formats, which are significantly different to those in Dai society. This is related to the tribal structure of De'ang society prior to its rule under the Dai tusi.

The most unique feature of the De'ang youth age group is its pairing of young men and women to establish a compulsory one-to-one partnership known as a "ku". The youth age group has a defined structure and membership system whereby the age group headman (po mau) must be a married male. Generally, there are two headmen, with one acting as chief headman, and the other as deputy headman. Both headmen are elected to manage the youth age group by the elderly age group. Under these headmen, an unmarried young man (hu mau) and woman (hu Oau) work as respective leaders of the male and female youth. All men and women who join the youth age group are required to be paired up by the "po mau", regardless of their personal wishes. This pairing process follows the rule that prohibits marriage between men and women with the same surname. There is also an unwritten rule that siblings of different sexes can join the youth age group at the same time, while one of two siblings of the same sex must wait until their sibling leaves before they can join the age group. ${ }^{6}$ No woman in the group is left single, and additional female members are not accepted unless a male requests an arranged partnership, known as a "ku". In such partnerships, the male usually refers to his partner as "a pia ku", and the female refers to hers as "a lian ku". Generally speaking, only a male can initiate a "ku" partnership. According to the narrative accounts collected by reporters

\footnotetext{
${ }^{6}$ In the author's opinion, this is to maintain gender balance in the youth age group, and it's also related to the fact that the De'ang people attach great importance to the seniority rules. In the past, if the eldest sister in the family was not married, the younger sister in a relationship would be censured by her parents, as it was considered offensive to the unmarried eldest sister.
} 
to date, only a small number of youths ultimately marry their "ku" partner. Some reporters suggest that this rate is about $10 \%$, while others believe it to be $20-30 \%$. Therefore, such partnerships are broadly considered forced social relationships rather than truly intimate ones. The majority of young men and women are interested in someone outside of their "ku" partnership, and these romantic relationships are socially accepted. However, in the activities of the youth age group, the "ku" partnership must always take precedence. All members must follow the leadership of the "po mau", despite their equal status. "Hu mau" and "hu $\theta a u$ " are responsible for arranging various events for "a pia" and "a lian", and retain the right to educate members who are absent from the events or break rules. If they cannot handle an issue themselves, it will be passed up to the "po mau". Regarding joining and leaving the youth age group, and the establishment of the "ku" partnership, one of the interviewees recalled that:

"I was the last 'hu $\theta$ au'. I had three consecutive 'ku' partnerships, first for two years with my future brother-in-law, who had sent me two baskets during two Water Splashing Festivals. After he got married, I had a two-year 'ku' partnership with another man, and then another lasting one year with a third man before I got married. I received a total of 5 baskets and 3 cigarette boxes. The cigarette boxes were returned to my three former partners when they got married. My husband didn't join the youth age group. He worked as a supply teacher in the Bangwai village for one year after he graduated. To marry me, he had to pay 50 yuan to the leader of youth age group. If he'd have joined the youth age group, he wouldn't have had to pay this."

"In the past, the 'po mau' would come to a girl's house with five or six young men to play the gourd pipe and persuade the girl's parents to have her join the youth age group. If the parents refused, saying that their daughter was too young, they would visit the parents again the next year, informing them that their child must join within the upcoming year, otherwise she wouldn't be invited again and would miss her opportunity. Girls could join the youth age group during the annual Water Splashing Festival, Door Closing Festival, or Door Opening Festival. After they were accepted, the 'po mau' would designate them a 'ku' partner, under the principle prohibiting partnerships between men and women with the same surname. Females in the youth age group had to have a 'ku' partner, but this wasn't the case for male members. Female members without 'ku' partners would feel ashamed."

"Some members would fight with their partners and refuse to resolve matters. Even in this situation, a female had to take care of her partner simply because he was her designated 'ku' partner. A female who did not give her partner a Tongpa (bag) in return for his gift of a basket would be judged by the "po mau'. This was a strict rule in the past."

In view of this, it seems that there were ritualistic requirements for joining the youth age group, along with a certain degree of social compulsion. Those who did not join the age group were considered "outsiders" in the society and excluded from 
public events. Exits from the age group were not based on the chronological ages of members, but on changes in their social identity. Any members who got married were automatically deemed to have left the youth age group.

This form of youth age group continued until approximately the end of the twentieth century. As young people began to leave to work and study, young men and women were no longer able to establish "ku" partnerships, and youth age groups tended to disband. This was the case until 2009, when youths from Chudonggua Village were invited to attend the national drumming competition. After this, they began to engage in various performances organized by the government, and 3 years later the youth age group was renamed the "performer group", with members aged between 30 and 50 years, all of whom were married. Currently, the group still follows the leadership system requiring two "po mau" (one in chief position and the other in deputy position) to manage the group, with the head of women's association in the village serving as the "hu Өau". The "ku" form of partnership no longer exists.

Like the youth age group, the elders categorized in the fourth grade of social age also have a defined format. The De'ang people in Santaishan consider those in the fourth social age grade as the elderly age group. Within this group, there is a leadership organization consisting of seven elderly males with specific titles and positions. The "dagang" (ta? kian) is the head of the elderly age group, whose overall responsibility is to coordinate, manage accounts, protect common property, and look after the elephant-foot drum. The "dadeli" ( $\mathrm{ta}^{\text {? }} \mathrm{tr}$ ri) is a specialized religious deacon, with knowledge of Dai language and the Dai calendar, as well as Buddhist scriptures. The "Dalamu" (ta' la:m) is the assistant responsible for the monk's rituals and daily life. The "Daban" ( $\mathrm{ta}^{\text {P }}$ ban) is in charge of purchasing materials. The "Dasudegang" ( $\mathrm{ta}^{\text {? }}$ sut $\mathrm{t} \gamma \mathrm{kan}$ ) is responsible for notification-related matters. The "Daxing" $\left(\mathrm{ta}^{2} \theta \mathrm{in}\right)$ is responsible for managing the area designated to chanting mantras. The "Daxinggan" (ta? Oin kan) is responsible for making cassocks for the monk. In fact, it is easy to see from these titles that this is an elderly group, as "ta" is a respectful address for an elderly male. These seven candidates are selected from within the elderly age group without specific terms of office, mainly depending upon their own preferences and physical health.

These seven elders are the key leaders of the elderly age group, and the "Dagang", head of the age group, is the specially elected leader. Each leader has specific responsibilities, and they work in coordination, following instructions and accepting assignments from the "Dagang". All decisions made within the elderly age group are based on democratic consultation. For example, in the selection of the head (po mau) of the youth age group, the final candidate is elected according to majority opinion after thorough deliberation about and discussion of the nominated candidates. The elderly age group also is responsible for organizing various religious ritual activities in the village. Not limited to Buddhist activities, they also organize events such as the village-heart sacrifice offering ceremony and worship of the mountain gods. The leadership team determines the specific times and format of activities, and the "Dasudegang" is responsible for notifying all villagers of these. Compared with the youth age group, the elderly age group is currently much more prominent. In 2018, the leadership team, chosen through by-election, was still 
functioning well, with team members working together and filling each of the seven positions.

Activities of the youth and elderly age groups The "a lian" and "a pia" who join the youth age group are entered into a communal lifestyle. The communal house of the village, the stilt house, ${ }^{7}$ is a place in which groups of young men as well as people from outside the village can stay overnight. The stilt house is generally considered a space for the youth age group, and the kyaung is considered the same for the elderly age group. During the 3 months after the annual Door Closing Festival, the elderly enter the kyaung once every 7 days to recite sutras. On the first night of entering the kyaung, all "a lian" spend the night in the stilt house, where they learn to play the drums at night. During this period of communal living, the youths not only acquire drumming skills, but also learn secret information regarding their tribal history and various religious rituals. This communal life undoubtedly strengthens the identity of members in the youth age group and creates strong bonds between them.

Young men and women in "ku" partnerships are obliged to exchange gifts and perform necessary rituals together in various festivals. The most important events of the year are the Water Splashing Festival, the three-month summer settlement festival starting with the Door Closing Festival and ending with the Door Opening Festival, and "bloi" or the Ganduo Festival in other villages after the Door Opening Festival. $^{8}$

When establishing a "ku" partnership, an "a lian" must give his "a pia" a silver cigarette box, which the "a pia" must use throughout her time in the youth age group. The "a pia" cannot use a cigarette box given to her by her real lover, otherwise she will be punished. When a man or woman automatically leaves the youth age group due to marriage, the woman is required to return the case to the man, and the remaining party is re-matched with a new "ku" partner.

For the gift exchange during the Water Splashing Festival, the "a lian" has to make flower baskets and water tubes for his "a pia ku", while the "a pia" has to make a Tongpa for her "a lian". On the first day of the festival, the "a lian" must carry the Tongpa made by his "a pia ku". He is only permitted to carry the Tongpa made by his real lover from the second day onwards, otherwise he will be punished. On the final day of the Water Splashing Festival, the "a pia" must prepare a sumptuous packet of rice and leave it quietly in the kitchen of her partner's house to express her gratitude. After the male partner has enjoyed the meal, he has to fill the packet

\footnotetext{
7 The stilt house, now demolished, was located next to what is now the first village group activity room. It was a single-story, open-plan building in the traditional pile-dwelling style.

8 Participation in "bloi" events is usually a collective congratulatory visit to another village for the construction of a new kyaung or pagoda, or for the promotion of a monk. Participation in the Ganduo Festival is to establish a circle of mutual visits between certain fixed villages, in the form of visits and return visits in turn. Since 2015, for the sake of saving time and labor cost, the villages participating in Ganduo Festival no longer visit each other, but take turns to be the host. The order of Chudonggua Village's participation in the Ganduo Festival is as follows: old Chudonggua Village-Laoguangxin (a Dai village located in Xuan'gang, which believes in the same sect as Chudonggua)-Fengchuipo (a De'ang village)—new Chudonggua Village — Lujiesa.
} 
with sweets the next day and give it to his "a pia" as a return gift. During the Water Splashing Festival, the youth age group is responsible for picking flowers from the mountains to decorate the Dragon Pavilion and fetch water for bathing the Buddha. After bathing the Buddha, the "a lian" must play the drum and "a pia" must dance and offer cigarettes and water to the elderly. In this way, the "ku" partnership completes the necessary rituals together.

During the three-month summer festival lasting from the Door Closing Festival until the Door Opening Festival, on the night before the elderly enter the kyaung, all "a lian" have to stay overnight in the stilt house and beat drums around it at night. No "a pia" are permitted to spend the night in the stilt house. The next morning, all "a pia" bring flowers for the Buddha, as well as their "a lian ku" and male relatives with the same surname as them in the youth age group. At the beginning of the ceremony, the flowers for the Buddha are placed in the kyaung by the "a lian". When the elders start to recite sutras in the kyaung, the "a lian" have to walk three times around the kyaung while beating drums. Both the "a liay" and "a pia" are also required to prepare meals for the elders.

When attending the Ganduo Festival outside of the village during the dry season (after November), the "a lian" must give his partner three pairs of flower-carved waistbands and an umbrella, and "a pia" must send her partner two cloth bags. If an "a liaj" does not give his partner a gift, she will have a valid reason not to attend the Ganduo Festival. Afterwards, the "a liay" has to apologize to the "po mau" and "hu mau" to admit his mistake. Young people who do not yet have a "ku" partner are free to decide whether they will attend the Ganduo Festival. If they do have a partner, they must participate, otherwise they will be punished.

The youth age group is tightly organized, internally disciplined, and closely united when facing outsiders. When visiting other villages to participate in "bloi" events and the Ganduo Festival, youth age groups from different villages usually compete with each other by singing songs and beating elephant-foot drums. Bangwai, a De'ang village with a predominantly "Bulie" clan, is separated from Chudonggua Village by a hill. According to Chudonggua villagers, their village and Bangwai jointly held the Ganduo Festival in the 1980s, and often had fierce confrontations during song and drumming competitions, rendering the results too close to call. Although the villagers of these two villages originate from same De'ang ethnic group and all practice Hinayana Buddhism, they each follow the teachings of their respective sects. When the youth age group of Bangwai sang lyrics that denigrated the teachings of Chudonggua during the song contest, this led to much tension and saber-rattling between the youth on both sides. Despite breaking drums during the competition, Bangwai did not defeat Chudonggua. After losing for 3 years in a row, Bangwai used tiger skin as a drum surface in the fourth year (only cowhide and sheepskin are traditionally allowed). After some unpleasant events, Chudonggua stopped attending the Ganduo Festival with Bangwai and would only participate in "bloi" events.

From the above, it is clear that young men and women in Chudonggua Village are paired up within the youth age group to establish compulsory one-to-one partnerships known as "ku" so that they can work together and participate in public rituals in the village. During the Ganduo Festival, the youth age group of Chudonggua 
unites against outsiders, resulting in ritualistic confrontation and competition with other youth age groups outside of the village, thereby strengthening the sense of identity and unity within their own village.

In contrast with the youth age group, the main activity of the elderly age group is to recite sutras in the kyaung. Elderly people with good mobility still participate in "bloi" and the Ganduo Festival outside of the village, but most of them tend to stay in the village to participate in kyaung activities. The main time of year dedicated to entering the kyaung to worship the Buddha is the 3 months after the Door Closing Festival. On the first day of entering the kyaung, the elderly prepare their offerings to the Buddha. These include flowers, rice, incense and candles, clean water, paper flags and some fruits and cookies. After entering the kyaung, the elderly place some of their offerings into a communal bamboo tray before taking their seats. Men and women are strictly separated, with men seated in front near the Buddha statue, and women in the back, separated from the men by some steps. The seating arrangement is based on age, with older people sitting closer to the statue and younger people sitting further away from it. The seating position of each person is essentially fixed, and the distinction between age and gender is clear at a glance. The hierarchy in the elderly age group is reflected in its age order. The older a person is, the higher their status, and the elderly have priority in the ceremony, while those who are younger naturally come second. Once everything has been prepared, the "ta? la:m" presents the offerings for the monk and invites him to come out and recite sutras, and the " $\mathrm{ta}^{\text {? }}$ tr ri" assists the monk in his recitations. The elderly listen to the monk and perform rituals such as chanting, kowtowing, and dripping water. When the elderly enter the kyaung to recite sutras, the youths must prepare meals for them to ensure that they can eat outside the kyaung once they have finished reciting sutras.

Functions of the youth and elderly age groups From the organizational forms of the youth and elderly age groups mentioned above, it is clear that their activities are based around Buddhist activities and annual festival ceremonies. In terms of their functions, the two age groups take on different roles in these activities. The elderly age group consists of mentors and those who practice religious activities. These individuals master religious knowledge and various religious rituals, and aspire to gain merit and pursue higher titles by performing bloi. On the other hand, the youth age group consists of learners and those who provide services during religious activities. They learn from the elderly how to perform and serve during the bloi. By participating in the bloi, they learn how religious activities operate and how they can live a "perfect" life that will be accepted in society. During the ceremonies, there is also clear division of labor and collaboration between the youth and elderly age groups. While the elderly pray to the Buddha and chant sutras in the kyaung, the youth have to circle the kyaung three times while beating drums, which remains an inherited and indispensable tradition today. The difference between these two groups in terms of functions can also be seen in their possession of symbolic resources.

Today, the water drum belongs to the youth age group and the elephant-foot drum belongs to the elderly age group. Each of these drums has their own operating logic and functions. In general, the water drum is considered to be the representative musical instrument of the De'ang people, while the elephant-foot drum is the 
same to the Dai people (Mubeimatu 2015). However, as unexpectedly discovered by the author while conducting research in the Chudonggua Village, the water drum is not used during major annual festival ceremonies such as the Water Splashing Festival, the Door Closing Festival, the Door Opening Festival, or the Firewood Festival, nor in family activities such as the $1 u^{2}$ t6om and lu? $\mathrm{s} \gamma \mathrm{tan}$ ceremonies. Only the elephant-foot drum is played on these occasions. The water drum is only played in external performances by the youth age group or on occasions that showcase the traditional culture of the De' ang people. Now, the water drum is kept in the youth activity room by head of the youth age group, "po mau", and the elephant-foot drum is kept in the home of the head of the elderly age group, " $t a$ ? kian".

The widespread use of the elephant-foot drum in the annual ritual of the De'ang people is closely related to the edification of traditions from the Dai tusi. The political management of the Dai tusi's ruling of the De'ang people is also related to the edification. Following political progress, there were a series of changes in social culture, such as the people's overall belief in Theravada Buddhism, and acquisition of language, music, dance $\&$ art, and the social organization system of the Dai people. The introduction and acquisition of the elephant-foot drum is the product of such a process. In fact, the tusi in Dehong hosted two annual competitions from the thirteenth century onwards: one was the elephant-foot drum competition held in spring, and the other was the horseback archery competition in autumn (Mubeimatu 2015). The story of the acquisition of the elephant-foot drum clearly explains how the De'ang people accepted the edification of the tusi, and this drum represents an important political resource for the leader of De'ang village. Today, the elephantfoot drum, a symbol of political power, is firmly in the hands of the elderly age group.

In contrast, the situation of the water drum is completely different. The water drum is sacred to the De'ang tribe, and most legends of its origin are related to kingship. The Drum God is the protector of De'ang people, and is therefore is worshipped by them. The De'ang people offer sacrifices to the Drum God before going into battle or beating drums during festivals (Wang et al. 2014). The water drum is mostly used to call for assembly in the army of the tribe, displaying its obvious military nature. The legend of the origin of water drum in Chudonggua Village is as follows:

“The water drum is the salvation of our De' ang prince. The Dai people used to call us 'Palaung', which means drifting on water. After falling into the water, he (the prince) held a piece of dead wood so that he could float. After the wood washed up on the bank, he finally went ashore. He wanted to keep the wood that saved his life, so he made a drum out of it. In the past, to assemble an army for war, you had to notify people in different tribes, and the sound of the water drum could be heard from far away."

The water drum, which is frequently played by members of the youth age group, has become a symbolic resource for them. The military nature of the water drum dance is obvious, as the features of a war dance are evident in the moves and melodies when it is played. As this is an intensive dance that requires great strength on the part of the dancers, only young people in the prime of their life can perform it. 
This stands in stark contrast to the elephant-foot drum. The drumbeat played by the De'ang people is slower than that played by the Dai people, causing it to sound more solemn and composed.

In short, the water drum and elephant-foot drum symbolize very different things. The water drum dance is clearly military in nature, maintaining a style of war dance that suits the temperament of young people, who are full of passion and competitive spirit. Meanwhile, the elephant-foot drum is used for political purposes, with a solemn and composed sound perfectly matching the calmness and sophistication of the elderly. The difference between the water drum and elephant-foot drum as symbols also highlights the different functions of the youth and elderly age groups.

\section{Evolution of the age groups of the De'ang people}

\section{Evolution of the youth age group}

As for the reason why "ku" partnerships are established between "a lian" and "a pia", there are three explanations.

“When a 'ku' partnership has not been established, an 'a liay' can't 'chuan' an 'a pia', ${ }^{9}$ as this is illegal and defiant against the elderly. If this act is discovered, they must apologize to the elderly. However, when a 'ku' partnership is established, this means the boy and girl have met the requirements of the village, and the act of dating an 'a pia' can be carried out."

“One long-lasting tradition is that after an 'a liay' and 'a pia' enter the youth age group, the 'a liay' has to form a 'ku' partnership with the 'a pia'. When the Water Splashing Festival arrives, the 'a liay' should gift a basket of flowers to his 'a pia', who should make a pair of bags for her 'a lian'. If a 'ku' partnership has not been established, the 'a liaj' can only date his 'a pia' in secret. If a boy is dating an 'a pia' and her 'a liay' is present, he must leave and give precedence to the 'a lian'."

“A 'ku' partnership involves taking care of each other and participating in activities together. The purpose of establishing a 'ku' partnership is to forge unity during community activities. In the past, there were several rules about this. For example, one should avoid meeting his/her 'ku' partner's parents on the road."

The former two explanations connect the "ku" partnership with dating, with the "ku" partnership taking precedence. Establishing a "ku" partnership is the first step in a relationship. It is against the customs to date prior to establishing a "ku" partnership, which is an act to be punished by the elderly with judicial power. It is easy

\footnotetext{
${ }^{9}$ Chuan a pia refers to dates between young men and women. Traditionally, De'ang people have special ceremonies and strict regulations in dating. For example, a young man must play gourd pipe near the house of the woman, and enter the house after the woman light the firepit. The woman's family should leave and the young man and woman can date by the firepit with proper language and demeanor.
} 
to see that the "ku" partnership is a mandatory social rule, the breaking of which is equal to breaking social custom. The rule of establishing a "ku" partnership is the same as that of marriage, so we can conclude that end goal of a "ku" partnership is marriage. However, from what we have learned from our interviews, the majority of "ku" partnerships do not end in marriage. This may be due to disparities between expectations and reality. A reasonable explanation is that along with changes in the times and society, continued implementation of this custom has become difficult. It is also possible that because the social conditions leading to the custom have changed over time, there is no longer any need to strictly implement it. Nevertheless, the rule still exists and "ku" partnerships are given high priority. The third explanation emphasizes the idea of unity in "ku" partnerships and the effect of this. So, why is the organizational form of the "ku" partnership important enough to have been preserved for so many years?

For an "a liay", the two most important physical skills are drumming and martial arts. After entering the youth age group, the "a lian" "s most important job is to learn to play the drum. Adult males of the De'ang ethnic group traditionally undertake martial arts, and are particularly strong in boxing, swordsmanship, and cudgel skills. These martial arts are passed down the generations by martial arts masters in the village, and there are special venues and systems dedicated to this. On the mountain at the entrance of Chudonggua Village now known as "Landscape Forest", there is a camp dedicated to martial arts training for young men. Before learning martial arts, an apprenticeship ceremony must be held at the firepit of the martial arts master's home. After completing the apprenticeship, young men can go into the mountains to practice martial arts for three consecutive years. Young men will generally set up camp in the martial arts field during the dry season. Women are not permitted to observe this practice. This is essentially a secret club in which young men learn and practice martial arts.

The De'ang army consisted of male adults who were engaged in farm work on a daily basis and became soldiers when war broke out. According to records, the De'ang People living on the west of the Lancang River were well-known for their bravery, and formed an important military force of the Kingdom of Nanzhao during the Tang Dynasty. "In Puzi in Yuedan, a place west of the Lancang River wellknown for horse breeding, there was the group of Wang Juzi, who valued strength" (Xiang 1962); "The Wang Juzi barbarians living on the west of the Lancang River were defeated by Shengluopi. They were brave and skilled at using spears on horseback. The did not need saddles when riding, nor shoes when walking. They wore short armor that only covered their chests and abdomens, leaving their arms and lower bodies exposed. With yak tails on their helmets, they ran like they were flying, and this included the women in the group. Wang Juzi would be pioneers whenever Nanzhao and the neighboring towns went to war."10 (Xiang 1962). The group of

\footnotetext{
10 According to Wang Wenguang, Wang Juzi refers to the soldiers recruited by Kingdom of Nanzhao, instead of an ethnic group. The soldiers were mainly on the west of the Lancang River, which includes the area from Baoshan, Dehong and Lincang of Yunnan to the northwest of Myanmar. Puzi barbarians, Wang barbarians and Sanpu originated from a same ethnic group, which was the antecedents of the De'ang, Bulang and Wa People.
} 
"Wang Juzi" refers to the soldiers that Nanzhao recruited from the Wang barbarians. (Wang and Chen 2013). "Juzi", which means warriors, refers to the daring and battle skills of the Wang Juzi, including those of the females. Wang Juzi pioneered in the wars of Nanzhao. During the Song Dynasty, the Kingdom of Jinchi established a special army force based on the tribe of Mang people, ${ }^{11}$ which consisted of male adults who did not participate in farm work, but instead in battles, hunting, and aviculture. This force was heavily attacked by the army of Yuan. During the Ming and Qing Dynasties, the armed forces of the De'ang people were defeated and merged with the army of the dominant empires, to protect the borderlands. The Mangshi tusi also used the force of the De'ang people to defend his own governing interests against the ever-evolving Jingpo people (Yunnan Ethnic Affairs Commission 1999).

Historically, the De' ang people had strong military forces. Therefore, it is safe to speculate that the form of the compulsory "ku" partnership between young men and women is in fact a remnant of military organization, with a military purpose, and that the "ku" partnership was designed to meet military needs. This phenomenon is easier to understand from the perspective of comparative study. The most representative example of age sets functioning for military purposes is the "age-regiment system" of the Ngwato people in Africa. Under this system, the entire tribe is divided into multiple regiments. Each regiment is composed of people of the same sex and age, and every adult in the tribe must join one of these regiments. Every few years, a regiment is established when eligible boys or girls are old enough to be set up as a group. Both male and female regiments have chiefs. In times of war, the male regiments formed the original tribal armies, while at other times they served as laborers. Afterwards, following the involvement of Western colonial forces, age regiments gradually lost their military functions. However, the regiment members' roles as productive laborers were greatly enhanced in various areas, such as in building dams, constructing schools and churches, building roads and airports, and arresting lawbreakers (Fortes and Evans-Pritchard 2016). Regarding the marriage principle for age regiments, references can be found and comparisons can be made in studies on the Zulu Kingdom of South Africa. During the reign of Shaka, all men were required to serve as full-time warriors, with men of the same age being grouped into the same regiments, and stationed in military camps for training all year round. They were forbidden to marry unless they had the king's approval for a group marriage between the men of the regiment and the women from a specific age group (Fortes and Evans-Pritchard 2016). The case of Zulu shows that the form of marriage in age regiments consisted of intermarriages between specific age groups whereby individual partners were designated.

For this reason, it is believed that the "ku" partnership of the De'ang people was originally passed down as a marriage rule from the military system. Historically, the youth age group of the De'ang people was designed for military purposes. As the

\footnotetext{
11 According to Fang Guoyu and Jiang Yingliang, Mang people were considered the antecedents of Dai people while Sang Yaohua thought they were antecedents of De'ang, Bulang and Wa people. In the Research of the Social and History of De'ang People, and the Brief History of De'ang People, the Kingdom of Jinchi was believed to be established by the De'ang, Bulang and Wa people.
} 
De'ang people came under the rule of the Dai tusi, their military power was weakened, and later, with the end of the tusi system, the military organization based upon this system failed and collapsed, causing the youth age group to essentially lose its military function. However, the water drum, a symbol of war, has been mastered and performed on by members of the youth age group, and the culture of youths practicing martial arts is still alive. The members of the youth age group are passionate, vigorous, and fond of challenges, which remains evident in their ritualistic confrontation and competition with other youth age groups outside of the village during the Ganduo Festival.

\section{Evolution of the elderly age group}

Compared with the historical title of "Dagang" as the head of the village, today's "Dagang" as the head of the elderly age group differs only in authority and function. The rule that only the elderly can serve in this position continues to be upheld. Before 1955, the De' ang people living in the Santaishan region were under the jurisdiction of the Dai tusi. They did not have independent political organizations and were managed by the head appointed by the tusi. The political organization of the De' ang was limited to the township and village levels, and the highest-level headman was called "Dagang" (meaning "chief head"), who was equivalent to the headman at the township level and responsible for managing several villages. Each village had a "Dajigang" (meaning "head"), who was equivalent to the headman at the village level. The "Dapulong", "Dajige" and other similar deputy heads assisted the "Dajigang" in dealing with matters in the village. ${ }^{12}$ Throughout the Santaisha region, there were only 3 people serving as "Dagang", and 10 as "Dajigang". Historically, there was only a "Dajigang" in the old Chudonggua Village, who was elected by the village elders and approved by the "Dagang" (Teng 2006).

The "Dajigang" was responsible for attending township-level meetings on behalf of the village, collecting various household levies and tributes to the tusi, arranging production, promoting household levies and miscellaneous taxes, maintaining social security, and mediating civil disputes. The elderly had the final say regarding the election of "Dagang" and "Dajigang". They dominated the internal politics of the village, and the "Dagang" was the political representative of the elderly. According to one study, "from the emergence and functions of the De' ang headman, the De' ang people have maintained the form of 'village community council' as a social group before they were ruled by tusi" (Teng Erzhao 2014). This "village community council" is an embodiment of elderly politics and the prototype of the leadership structure used by the elderly age group today. In the past, the "village community council" composed of the elderly was responsible for mediating civil disputes, making decisions on public affairs, managing religious matters, deciding on war declarations, attending Ganduo Festival activities outside of the village, and so on.

\footnotetext{
12 Yunnan Provincial Compilation Group (云南省编写组). 2009. 德昂族社会历史调查Social and Historical Survey of De'ang People. Materials were marked only with Chinese transliteration, not with international phonetic symbols. Beijing: The ethnic Publishing house.
} 
The elderly age group serving political and ritualistic functions is a relatively common phenomenon in tribal societies. In some tribes in East Africa, elderly politics are institutionalized through a defined structure of age sets and age grades (Fortes and Evans-Pritchard 2016). "The engagement of the elderly is the most indispensable factor in political leadership as this is socially marked through the circumcision system in age sets, and the elderly's authority is further reinforced by ancestor worship. Meanwhile, the involvement of the elderly is necessary in sacrifices as these rituals require an individual to be free from sexual desire, with elderlike merits, such as wisdom, gentleness, and the absence of greed and envy" (Fortes and Evans-Pritchard 2016). Today, all rituals in Chudonggua Village continue to be organized and arranged by the elderly age group.

Therefore, the youth and elderly age groups have historically served different social functions and roles. The former works for military purposes in the society, with passionate, competitive, and aggressive qualities, while the latter undertakes political, judicial, and ritual activities, while embodying wisdom, composure, and gentleness.

After the De'ang people came under the rule of the Dai tusi, Southern Theravada Buddhism developed vigorously in the De'ang region. The dominance of Buddhism in the De'ang society became increasingly influential. In order to educate the De' ang people, the Dai tusi invited monks from Mubang, Burma, to build Buddhist temples in De'ang villages, promote Buddhist teachings and regulations, and cultivate the De' ang monks. Buddhism then spread rapidly through De' ang society (Tang 2012). The Buddhist society attempted to reshape social roles and values of individuals of different ages, and the "social age structure" of the entire society was thus reflected in the division of roles and values of different ages, centering on performance of the "bloi" ritual. The original function of age groups was also transformed. The military function of the youth age group in the category of the second social age grade was transformed into religious and ritualistic functions ${ }^{13}$ (Jiang 2003). Meanwhile, the elderly age group categorized in the fourth social age grade fundamentally maintained their political, judicial, and sacrifice functions from the era in which they were under the rule of tusi. With the introduction of modern village power in the De' ang villages, the elderly age group gradually lost their political and judicial functions, only retaining the sacrificial and religious functions. The places available for the elderly age group to arrange related activities are also limited to kyaungs, and the leadership structure is established based on Buddhist events in temples.

\footnotetext{
13 According to Jiang Yingliang, Buddhist beliefs have profoundly transformed the warlike character of the Dai people, and their brave and militant character has become tender and kind through Buddhist education. Only the usual armament facilities in the Tusi Office show the warlike trace of the original tribal peoples.
} 


\section{Conclusion}

The De'ang people use an age class system that divides the different stages of life into four consecutive age grades, representing the roles, status, and values of these different life stages. Only the second and fourth age grade are organized in a way that follows the respective forms of the military (youth age group) and political (elderly age group) organizations from the tribal era. With the introduction of these two forms in the local Buddhist society, their functions evolved into the division of roles in religious activities. Therefore, unlike the African age sets examined in anthropological studies, the age groups of the De' ang people form a special type of "age-grade organization". The significance of the De'ang case is that it provides a unique organizational form compared with the basic types found in the age class system, and serves as important reference for further discussion of the relationship between age sets and age grades, and the morphological types of the age class system.

Acknowledgements It was written with the help of Zhang Yahui at Xiamen University and Chu Jianfang at Nanjing University. The author would like to express sincere gratitude to them.

Author's contributions Yu Shu have done all the work of this paper. The author read and approved the final manuscript.

Authors' information Yu Shu, Associate Researcher.

Funding This paper is an important progress made by the innovation project under the Institute of Ethnology and Anthropology, Chinese Academy of Social Sciences, "Research on the Building of Ecological Interest Community and the Transformation of Livelihood Models in Ethnic Minority Areas" (Project No.: 2019MZSXK009).

Availability of data and materials Available from the author upon request.

\section{Declarations}

Ethics approval and consent to participate Before taking the participants' interview, the author obtained their oral consent. They understood the purpose and significance of the survey. They can also leave the interview at any time. All recordings were made with their consent.

Consent for publication Not applicable.

Competing interests We have no any competing interests.

Open Access This article is licensed under a Creative Commons Attribution 4.0 International License, which permits use, sharing, adaptation, distribution and reproduction in any medium or format, as long as you give appropriate credit to the original author(s) and the source, provide a link to the Creative Commons licence, and indicate if changes were made. The images or other third party material in this article are included in the article's Creative Commons licence, unless indicated otherwise in a credit line to the material. If material is not included in the article's Creative Commons licence and your intended use is not permitted by statutory regulation or exceeds the permitted use, you will need to obtain permission directly from the copyright holder. To view a copy of this licence, visit http://creativecommons.org/licen ses/by/4.0/. 


\section{References}

Chu，J. (禇建芳). 2005. 人神之间:云南芒市一个傣族村寨的仪式生活、经济伦理与等级秩序 (between people and gods: The ritual life, economic ethics and hierarchical order of a Dai Village in Mangshi, Yunnan), Beijing: Social Sciences Academic Press (社会科学文献出版社), pp.98-112.

Eisenst, S.N. 1954. African age groups: A comparative study. Journal of the International African Institute 24: 2 .

Encyclopedia Britannica Online with the URL: https://school.eb.com/levels/high/search/articles?query= age+set. n.d.

Fortes, M., and E.E. Evans-Pritchard 2016. 非洲的政治制度. Chinese edition: Beijing: The commercial press. (trans: Liu, Zhen 刘真). African political systems from the 1987 edition. New York: Routledge.

Huang, X. (黄宣卫). 2000. 区域历史、族群关系与文化变异:从文献资料初探阿美族文化的地域 性差别(Regional History, Ethnic Relations and Cultural Variation: A preliminary Study on the Regional Differences of Amis Culture from the Literature) 族群、历史与空间:东台湾社会与 文化的区域研究研讨会论文集(Proceedings of a Symposium on Ethnicity, History, and Space: Regional Studies of Eastern Taiwan Society and Culture).

Jiang, Y. (江应樑). 2003. 滇西摆夷之现实生活 (real life of Bai (Dai) ethnic Group in Western Yunnan). Mangshi (China): Dehong Ethnic Publishing House.

Luo, H. (罗红). 2008. 白族社会性别结社与族群认同(gender association and ethnic identity in the Society of Bai People). 云南民族大学学报(社会科学版). Journal of Yunnan Minzu University (Social Sciences). (Social Sciences), No.6.

Ma, T. (马腾获). 2015. 鹤庆白族年龄组织“帮辈”文化的人类学初探 (an anthropological probe into the culture of peer helping in age groups of Bai people in Heqing). 西南边疆民族研究 Research on Chinese Southwest's Borderland Ethnic Minorities. Vol. 16.

Mubeimatu (穆贝玛途). 2015. 大美德宏一德宏傣族景颇族自治州非物质文化遗产荟萃The great beauty of Dehong - a collection of intangible cultural heritages in Dehong Dai and Jingpo autonomous prefecture. Mangshi (China): Dehong Ethnic Publishing House.

Stewart, F.H. 1977. Fundamentals of age-group systems, 28-29. New York: Academic pp.130-131.

Tang, J. (唐洁). 2012. 中国德昂族 (De'ang people in China). Yin Chuan (China): Ningxia People's Publishing House.

Teng, E. (腾二召). 2006. 古老的茶农一中国德昂族社会发展变迁史(ancient tea farmers - history of social development and changes of De'ang people in China). Kunming: Yunnan Ethnic Publishing House.

Tien, Ju-Kang. 2008. 芒市边民的摆(religious cults of the Pai-I along the Burma-Yunnan border), 91. Kunming: Yunnan People's Publishing House.

Tien, Ju-Kang. 2015. 滇缅边地摆夷的宗教仪式. Chinese edition: Shanghai: Fudan University press (trans: Yu cuiyan, ma Shuo). Religious cults of the Pai-i along the Burma-Yunnan border. Cornell University. 1986.

URL for Wikipedia entries of age-set and age grade: https://en.wikipedia.org/wiki/Age_set. n.d.

Vivanco, Luis A. 2018. A dictionary of cultural anthropology (electronic version). Oxford: Oxford University Press.

Wang, W. and Y. Chen (王文光、陈燕). 2013. 南诏国境内外的望蛮、朴子蛮、三幞研究(Study on Wang Man, Pu-zi Man, and San Pu around the Nanzhao Territory). Journal of Guangxi University For Nationalities (Philosophy and Social Science Edition). No.5.

Wang, X., L. Mo and Y. Qin (王晓艳、莫力、秦芗编著). 2014. 德宏德昂族民间科学技术 (folk science and Technology of De'ang people in Dehong). Mangshi (China): Dehong Ethnic Publishing House. pp. 168.

Wu, C. (吴春明). 1999. 试论惠东妇女长住娘家婚俗的起因(on the origin of Huidong Women's marriage custom of "long stay in their parents' home"). Ethno-national Studies. No.2.

Xiang, D. (向达). 1962. 蛮书校注(collation and annotation of man annals). Beijing: Zhonghua Book Company.

Yejingzhumu (叶静珠穆). 2010. 藏区村寨年龄组织个案调查一以松潘热务沟卡卡村为例 (a case study of age-set Organization in a Tibetan Village_— Taking Kaka Village in Songpan Rewu Valley as an example). Journal of Tibet University (Social Sciences) (西藏大学学报社会科学版). No.2. 
Yunnan Ethnic Affairs Commission (云南省民族事务委员会). 1999. 德昂族文化大观( a general view of De'ang culture). Kunming: Yunnan Ethnic Publishing House. pp. 144-145.

\section{Comments}

Publisher's Note Springer Nature remains neutral with regard to jurisdictional claims in published maps and institutional affiliations. 